\title{
4-Cyano-3-oxotetrahydrothiophene (c-THT): An Ideal Acrylonitrile Anion Equivalent
}

\author{
François Richarda (D) \\ Carlos Mateos ${ }^{b}$ (D) \\ Stellios Arseniyadis*a (D) \\ ${ }^{a}$ Queen Mary University of London, \\ School of Biological and Chemical Sciences, London, E1 4NS, UK \\ s.arseniyadis@qmul.ac.uk \\ b Centro de Investigación Lilly S.A., Avda. de la Industria 30, \\ Alcobendas-Madrid 28108, Spain \\ Dedicated to Professor K. C. Nicolaou on the occasion of his $74^{\text {th }}$ birthday
}
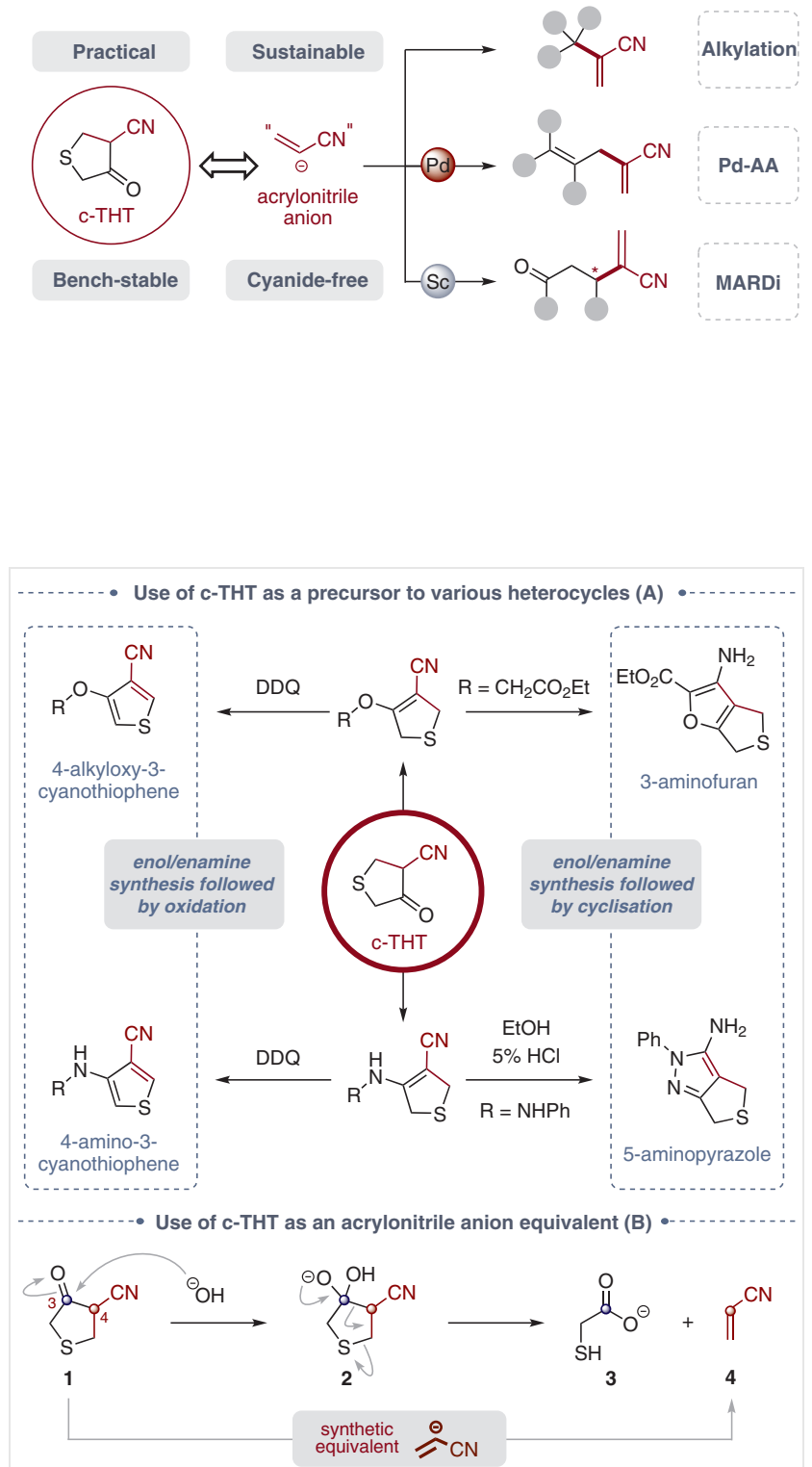

Scheme 1 Retro-Dieckmann fragmentation of c-THT

lides using potassium carbonate as a mild base and running the reaction in acetone, the crude intermediate $\mathbf{5}$ was subsequently fragmented at room temperature using $5 \%$ aqueous sodium hydroxide in a biphasic water/Et ${ }_{2} \mathrm{O}$ system (Scheme 2). This two-step sequence afforded a particularly straightforward access to a variety of $\alpha$-substituted acrylonitriles $\mathbf{6}$ in moderate to good yields.

More recently, Leiros, Bayer and co-workers took advantage of Baraldi's methodology to prepare new metallo- $\beta$ lactamase inhibitors (Scheme 3$)^{5}$ Their strategy relied on 


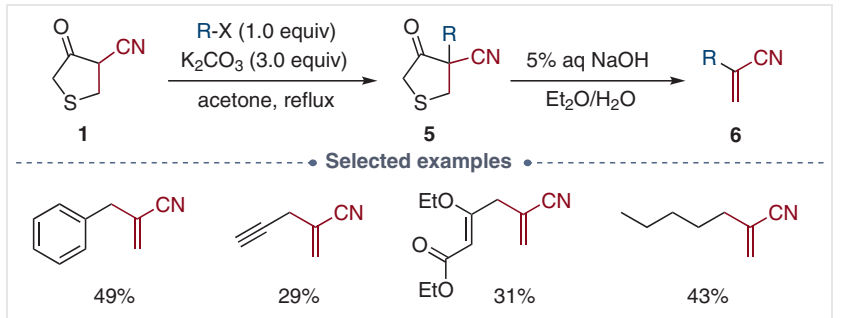

Scheme 2 Selected examples of $\alpha$-substituted acrylonitriles obtained by alkylation followed by retro-Dieckmann fragmentation of c-THT

the use of c-THT to incorporate an acrylonitrile moiety, which could then be used as a true launching pad for further modifications. Hence, after alkylation following Baraldi's protocol, the key intermediate $\mathbf{7}$ was converted into the corresponding vinyl tetrazole 8 upon heating in dioxane at $150{ }^{\circ} \mathrm{C}$ under MW irradiation in the presence of $\mathrm{TMSN}_{3}$ and a catalytic amount of $n-\mathrm{Bu}_{2} \mathrm{SnO}$ (78\% yield). The latter proved to be an excellent Michael acceptor and allowed the introduction of various thiol moieties in high yields.

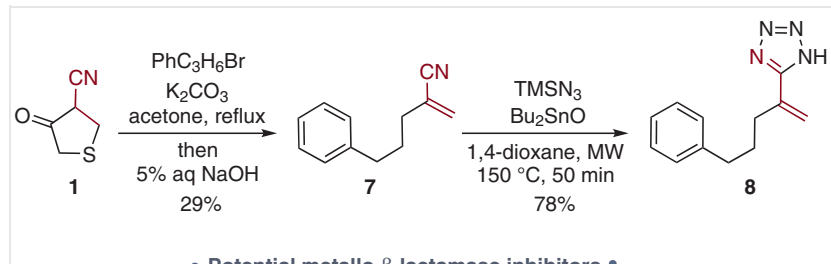<smiles>c1ccc(CCCC(CCSC2CCCCC2)c2nnn[nH]2)cc1</smiles><smiles>SCCC(CCCc1ccccc1)c1nnn[nH]1</smiles>

Scheme 3 Synthesis of metallo- $\beta$-lactamase intermediates through sequential alkylation/retro-Dieckmann fragmentation

\section{Biographical Sketches}
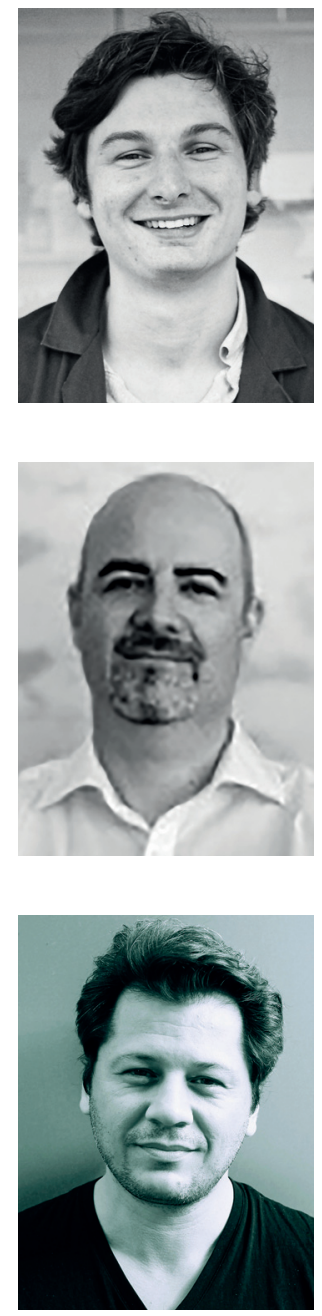

François Richard first earned a Technical Degree in Chemistry from the Institut Universitaire de Technologie of Orsay and then joined the Ecole Nationale Supérieure de Chimie de Montpellier (ENSCM). His educational

Carlos Mateos obtained his degree in Organic Chemistry in 1998, in the University of Oviedo (Spain). Then, he moved to Leverkusen (Germany) to enjoy an industrial internship in Bayer AG. In 1999, he moved back to

Stellios Arseniyadis received his PhD from the University of Strasbourg under the guidance of Dr. C. Mioskowski. After various postdoctoral stints in industry (Rhodia Chirex, Boston, USA, in collaboration with Prof. S. L. Buchwald, MIT) and in academia background allowed him to get industrial placements at Bayer CropScience (Lyon) and Syngenta (Stein). In March 2017, he joined the Arseniyadis group at Queen Mary University of London for his masters thesis and started his $\mathrm{PhD}$ in collaboration with Lilly. His research focuses on the construction of complex architectures via metal-catalysed asymmetric allylic alkylation and $\mathrm{C}-\mathrm{H}$ activation processes.
Spain to pursue a $\mathrm{PhD}$ under the supervision of Prof. José Barluenga. In 2004, Carlos joined the CRO Galchimia (Santiago de Compostela, Spain) as a project manager. In 2006, he joined Lilly (Alcobendas, Spain) where he is currently working in the MedChem group. His main research interests include drug discovery, flow chemistry, process development and external R\&D collaborations.
(Prof. A. C. Spivey - Imperial College London and Prof. K. C. Nicolaou - The Scripps Research Institute), he started his academic career in France first as a permanent CNRS researcher and later as a CNRS Director earning the CNRS Bronze Medal in 2015. The same year, he moved to Queen Mary University of London where his group is interested in developing new methods for more efficient and sustainable organic syntheses. 
Our group has also been interested in evaluating the synthetic potential of c-THT as an acrylonitrile anion equivalent, deeply convinced that it could be used in a broader range of reactions. Encouraged by the results we obtained over the years in the field of palladium-catalysed allylic alkylation, ${ }^{6}$ we logically became interested in applying this strategy to c-THT with the idea of generating 1,4-dienes (Scheme 4). Interestingly, subjecting c-THT to a sequential palladium-catalysed allylic alkylation/retro-Dieckmann fragmentation afforded a highly straightforward and scalable route to the desired 1,4-dienes $\mathbf{1 1}$ bearing an acrylonitrile moiety. ${ }^{7}$ The latter were eventually converted into various useful building blocks using biocatalytic transformations.

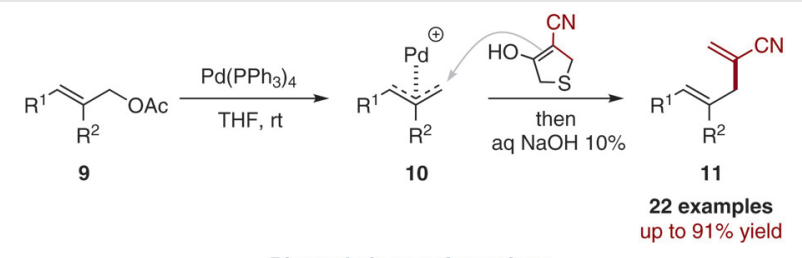

$$
\begin{aligned}
& \underset{\substack{12 \\
(2 \% \text { yield } \\
(\mathrm{ee}=92 \%)}}{\begin{array}{c}
\text { Ene reductase } \\
\text { ERESK-9600 }
\end{array}}
\end{aligned}
$$

Scheme 4 Sequential Pd-catalysed allylic alkylation/retro-Dieckmann fragmentation of c-THT followed by biocatalytic transformations

Encouraged by these results, which provided clear evidence of c-THT's compatibility with metal-catalysed transformations, and with the idea of developing an enantioselective method to incorporate an acrylonitrile moiety onto a pro-chiral substrate, we set out to evaluate the feasibility of an asymmetric one-pot Michael addition/retro-Dieckmann fragmentation (MARDi). To our satisfaction, this one-pot, two-step sequence featuring a highly enantioselective scandium-catalysed Michael addition was successfully applied to $\alpha, \beta$-unsatured-2-acylimidazoles $14,{ }^{8}$ affording the corresponding acrylonitrile-containing derivatives in both high yields and excellent enantioselectivities (up to 96\% ee) (Scheme 5). ${ }^{9}$ Interestingly, tetrabutylammonium hydroxide (TBAH, $1 \mathrm{M}$ in methanol) was used instead of aqueous sodium hydroxide to prevent a potential erosion of the enantiomeric excess.

Most importantly, to demonstrate the synthetic utility of the resulting enantioenriched $\alpha$-substituted acrylonitriles, several post-functionalisations were performed, affording some particularly interesting building blocks for natural product synthesis.

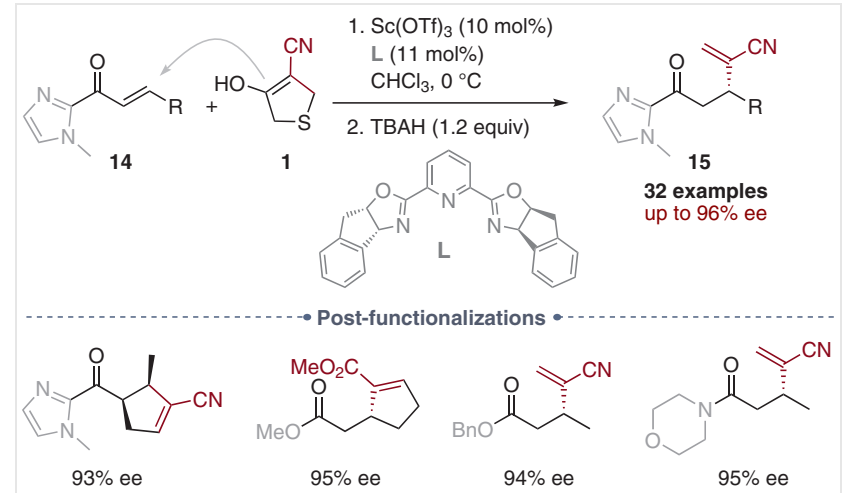

Scheme 5 One-pot sequential asymmetric Michael addition/retroDieckmann fragmentation

In summary, c-THT has become a go-to reagent when wanting to introduce an acrylonitrile moiety within a molecule. Considering the importance of the acrylonitrile motif in medicinal, agrochemical and polymer chemistry, there is no doubt that this acrylonitrile anion equivalent will become an essential tool in the synthetic chemist's toolbox.

\section{Funding Information}

Eli Lilly and Queen Mary University of London are gratefully acknowledged for financial support.

\section{References}

(1) (a) Hergué, N.; Mallet, C.; Savitha, G.; Allain, M.; Frère, P.; Roncali, J. Org. Lett. 2011, 13, 1762. (b) Moussallem, C.; Olivier, S.; Grolleau, J.; Allain, M.; Mallet, C.; Savitha, G.; Gohier, F.; Frère, P. Chem. Eur. J. 2016, 6510.

(2) Redman, A. M.; Dumas, J.; Scott, W. J. Org. Lett. 2000, 2, 2061.

(3) Kovács, D.; Molnár-Tóth, J.; Blaskó, G.; Fejes, I.; Nyerges, M. Synth. Commun. 2015, 45, 1675.

(4) Baraldi, P. G.; Pollini, G. P.; Zanirato, V.; Barco, A.; Benetti, S. Synthesis 1985, 969.

(5) Skagseth, S.; Akhter, S.; Paulsen, M. H.; Muhammad, Z.; Lauksund, S.; Samuelsen, Ø.; Leiros, H. K. S.; Bayer, A. Eur. J. Med. Chem. 2017, 135, 159.

(6) (a) De Oliveira, M. N.; Arseniyadis, S.; Cossy, J. Chem. Eur.J. 2018, 24, 4810. (b) Song, T.; Arseniyadis, S.; Cossy, J. Org. Lett. 2019, 21, 603. (c) Aubert, S.; Katsina, T.; Arseniyadis, S. Org. Lett. 2019, 21, 2231. (d) De Oliveira, M.. N.; Fournier, J.; Arseniyadis, S.; Cossy, J. Org. Lett. 2017, 19, 14. (e) Fournier, J.; Arseniyadis, S.; Cossy, J. Angew. Chem. Int. Ed. 2012, 51, 7562. (f) Fournier, J.; Lozano, O.; Menozzi, C.; Arseniyadis, S.; Cossy, J. Angew. Chem. Int. Ed. 2013, 52, 1257. (g) Arseniyadis, S.; Fournier, J.; Thangavelu, S.; Lozano, O.; Prevost, S.; Archambeau, A.; Menozzi, C.; Cossy, J. Synlett 2013, 2350. (h) Elhachemia, H.; Cattoen, M.; Cordier, M.; Cossy, J.; Arseniyadis, S.; Ilitki, H.; El Kaïm, L. Chem. Commun. 2016, 52, 14490. (i) Song, T.; Arseniyadis, S.; Cossy, J. Chem. Eur. J. 2018, 24, 8076. (j) Kerim, M. D.; Cattoen, M.; Fincias, N.; Dos Santos, A.; Arseniyadis, S.; El 
Kaïm, L. Adv. Synth. Catal. 2018, 360, 449. (k) Kerim, M. D.; Katsina, T.; Cattoen, M.; Fincias, N.; Arseniyadis, S.; El Kaïm, L. J. Org. Chem. 2020, 85, 12514.

(7) Katsina, T.; Sharma, S. P.; Buccafusca, R.; Quinn, D. J.; Moody, T. S.; Arseniyadis, S. Org. Lett. 2019, 21, 9348.
(8) (a) Lauberteaux, J.; Pichon, D.; Baslé, O.; Mauduit, M.; Marcia de Figueiredo, R.; Campagne, J. M. ChemCatChem 2019, 11, 5705. (b) Mansot, J.; Vasseur, J. J.; Arseniyadis, S.; Smietana, M. ChemCatChem 2019, 11, 5686.

(9) Duchemin, N.; Cattoen, M.; Gayraud, O.; Anselmi, S.; Siddiq, B.; Buccafusca, R.; Daumas, M.; Ferey, V.; Smietana, M.; Arseniyadis, S. Org. Lett. 2020, 22, 5995. 